\title{
A ORALIDADE NA SALA DE AULA: UMA PROPOSTA DIDÁTICA COM NOTÍCIA DE RÁDIO
}

\section{ORAL LANGUAGE IN THE CLASSROOM: AN EDUCATION STRATEGY WITH RADIO NEWS GENRE}

\author{
Maria de Fátima de Mello \\ Marlúcia Maria Alves ${ }^{2}$ \\ Maria Aparecida Resende Ottoni ${ }^{3}$ \\ Talita de Cássia Marine ${ }^{4}$ \\ Universidade Federal de Uberlândia
}

\section{RESUMO}

O objetivo deste artigo é apresentar uma proposta didática que traz como foco práticas de oralidade implementadas em uma turma de sétimo ano em uma escola municipal em Valparaíso de Goiás. A metodologia utilizada foi a pesquisa-ação. Nosso trabalho é baseado em Marcuschi (2001) Fávero (2000) e Fávero et al (2014), que abordaram a relação entre fala e escrita e a necessidade de aprimorar a modalidade oral da linguagem. Assim, foi elaborada uma sequência didática, baseada no modelo de Dolz, Noverraz e Schneuwly (2013), com o gênero notícia de rádio, estudados por Baltar (2012) e Ferraretto (2008), com a finalidade de contribuir para a ampliação do desempenho comunicativo e linguístico dos alunos, bem como promover um maior envolvimento deles com a disciplina de Língua Portuguesa.

PALAVRAS-CHAVE: Práticas de oralidade; Notícia de rádio; Desempenho comunicativo

\begin{abstract}
This article aims to present a didactic proposal which focuses on the orality practices implemented in a 7th grade class of a municipal school of Valparaíso, Goiás. The methodology applied was action research. Our work was based on Marcuschi (2001), Fávero (2000), and Fávero et al (2014). These studies show the relation between orality and writing and the need to work with the oral modality of the language. Therefore, a didactic sequence was elaborated based on the Dolz, Noverraz, and Schneuwly (2013) model with Baltar (2012) and Farraretto (2008) radio news genre. The aim was to contribute to the expansion of the communicative and linguistic development of the students as well as to promote more involvement between these students in the Portuguese Language course.
\end{abstract}

KEYWORDS: Orality practices; Radio News; Communicative performance

\footnotetext{
${ }^{1}$ Mestre em Letras pelo Programa de Pós-Graduação Mestrado Profissional em Letras (Profletras) do Instituto de Letras e Linguística (ILEEL) da Universidade Federal de Uberlândia (UFU). E-mail: fatima.1407@hotmail.com

2 Professora do Núcleo de Língua Portuguesa e Linguística e do Programa de Pós-Graduação Mestrado Profissional em Letras (Profletras) do Instituto de Letras e Linguística (ILEEL) da Universidade Federal de Uberlândia (UFU). Email: marlucia.alves@gmail.com

${ }^{3}$ Professora do Núcleo de Língua Portuguesa e Linguística e do Programa de Pós-Graduação Mestrado Profissional em Letras (Profletras) do Instituto de Letras e Linguística (ILEEL) da Universidade Federal de Uberlândia (UFU). Email: cidottoni@gmail.com

${ }^{4}$ Professora do Núcleo de Língua Portuguesa e Linguística e do Programa de Pós-Graduação Mestrado Profissional em Letras (Profletras) do Instituto de Letras e Linguística (ILEEL) da Universidade Federal de Uberlândia (UFU). Email: talita.marine@gmail.com
} 


\section{INTRODUÇÃO}

Este trabalho tem o objetivo de apresentar uma proposta de análise e produção do gênero notícia de rádio.

A partir de estudos realizados por Marcuschi (2001), Fávero (2000), Fávero et al. (2014), Baltar (2012), entre outros, verificou-se que a escola ainda centra suas atividades na modalidade escrita da língua, fazendo-se necessária a elaboração de propostas didáticas voltadas para a modalidade oral. De acordo com os Parâmetros Curriculares Nacionais - PCN, o ensino de língua materna deve ter como ponto central o uso de textos escritos e orais.

Há a necessidade de um trabalho de integração fala/escrita na escola, tendo em vista que o estudo da oralidade merece ocorrer paralelamente ao da escrita, pois o oral e o escrito se diferenciam por escolhas feitas pelo locutor/enunciador, determinadas pela adequação a cada modalidade em cada um dos gêneros discursivos por meio dos quais elas se manifestam. Além disso, é preciso observar a importância do suporte que permite a efetivação do discurso/texto, o contexto em que se encontram os interlocutores e a interação que se estabelece entre eles (Fávero et al, 2014).

Em relação à interação, as autoras destacam que "todo discurso se desenvolve em determinado contexto situacional e, muitas vezes, situação e contexto são utilizados como sinônimos" (FÁVERO et al, 2014, p. 17). Explicam ainda que é possível tratar a situação linguística, situação discursiva, contexto linguístico e contexto discursivo e acrescentam a importância de lembrar que a situação é o espaço físico, externa ao ato verbal, e se constitui de condições de realização. Portanto, "a situação diz respeito ao espaço de troca que acontece na relação com o interlocutor. Já o contexto, corresponde ao espaço textual, ou seja, é interno ao ato verbal". (FÁVERO et al, 2014, p. 17).

Marcuschi (2001) observa que, em relação às marcas de oralidade presentes na escrita dos alunos, é um equívoco do professor encarar como "erro" essas marcas, pois a escola ainda não mostra claramente as diferenças e especificidades de cada modalidade, justamente porque dá prioridade à língua escrita, deixando de lado ou em segundo plano a língua oral.

Considerando a relevância de se trabalhar oralidade e escrita paralelamente, procuramos desenvolver uma proposta de trabalho baseada na sequência didática (Dolz, Noverraz e Schneuwly, 2013) com o gênero notícia de rádio. Esse gênero foi escolhido porque contempla as duas modalidades da língua, a oral e a escrita. Além disso, acreditamos que características textuais como objetividade, concisão e clareza são aspectos que podem contribuir para incentivar o aluno a se informar sobre os acontecimentos do cotidiano. Nosso objetivo é oferecer atividades com práticas de oralidade que possam ser adaptadas e aplicadas por professores de outras disciplinas, isto é, não só por professores de Língua Portuguesa.

A metodologia utilizada foi a pesquisa-ação que possibilita a aproximação do pesquisador ao contexto pesquisado e é muito utilizada na educação, tendo em vista a resolução de problemas com vistas à transformação da realidade observada (THIOLLENT, 2011).

Este artigo está organizado em cinco seções: na primeira, apresentaremos o conceito de Gêneros Discursivos. A segunda abordará aspectos que constituem a Oralidade. Na terceira, justificaremos a escolha do gênero Notícia de rádio. Na quarta seção, faremos a Apresentação da proposta e, na quinta e última seção, exibiremos uma sequência didática com o gênero notícia radiofônica a ser desenvolvida em uma turma do sétimo ano do Ensino Fundamental. Iniciaremos com a noção de gêneros.

\section{Gêneros discursivos}

Desde a década de 80 estudiosos e pesquisadores intensificam reflexões sobre o ensino de Língua Portuguesa, com o objetivo de buscar novas abordagens e concepções de ensino de língua 
materna. Assim, a concepção prescritiva e normativa da gramática tradicional vem sendo substituída por uma concepção cujo foco é o texto.

Essa mudança de postura ocorre a partir de teorias como a de Bakhtin que enfatiza os conceitos de dialogismo, interação verbal e gêneros discursivos. Estes conceitos impulsionaram novas práticas pedagógicas quando o texto passa a ser a base de todo o trabalho de ensino e aprendizagem de língua materna.

A obra de Bakhtin tem nítida influência nos PCN editados no final da década de 90 . O documento incorporou a ideia da necessidade de exposição à diversidade de gêneros de circulação social como um dos princípios básicos do ensino de Língua Portuguesa, ressaltando a representatividade dos gêneros nas práticas comunicativas diárias como um dos critérios para a escolha dos materiais de leitura.

A noção de gênero, tradicionalmente utilizada no domínio da retórica e da literatura, baseia-se na obra de Bakhtin, à qual se referem muitos autores contemporâneos como, por exemplo, Schneuwly.

Cada esfera de troca social elabora tipos relativamente estáveis de enunciados: os gêneros; Três elementos os caracterizam: conteúdo temático, estilo, construção composicional; A escolha de um gênero se determina pela esfera, pela temática, pelo conjunto dos participantes e pela vontade enunciativa ou intenção do locutor (SCHNEUWLY, 2013, p. 23).

No Brasil, além desses, encontramos diversos autores que definem gêneros partindo das proposições bakhtinianas, entre eles Luiz Antônio Marcuschi que destaca a impossibilidade de não se comunicar verbalmente por algum gênero, por algum texto. "Isso porque toda a manifestação verbal se dá por meio de textos realizados em algum gênero. Daí a centralidade da noção de gênero no trato sociointerativo da produção linguística" (MARCUSCHI, 2008, p. 154).

Para Marcuschi, a escola, ao trabalhar com gêneros, tem a oportunidade de observar tanto a oralidade como a escrita em seus usos culturais mais autênticos sem recorrer à criação de gêneros que circulam apenas no seu contexto.

Bakhtin destaca que "os diversos campos da atividade humana estão ligados ao uso da linguagem" (BAKHTIN, 2010, p. 261). Para o filósofo russo, o emprego da língua se dá por enunciados orais e escritos, isto é, ditos pelos integrantes dos diversos campos da atividade humana e estes enunciados refletem condições e finalidades por meio do conteúdo temático, estilo da linguagem e construção composicional. $O$ autor ressalta ainda que cada enunciado particular é individual, mas cada campo de utilização da língua "elabora seus tipos relativamente estáveis de enunciados, os quais denominamos gêneros do discurso" (BAKTHIN, 2010, p. 262). Ele também destaca as infinitas possibilidades da atividade humana.

A riqueza e a diversidade dos gêneros do discurso são infinitas porque são inesgotáveis as possibilidades da atividade humana e porque em cada campo dessa atividade é integral o repertório de gêneros do discurso que cresce e se diferencia à medida que se desenvolve e se complexifica em determinado campo (BAKHTIN, 2010, p. 262).

Pelo exposto, observa-se a influência bakhtiniana no documento que é referência para elaboração de matrizes para a Educação Básica no Brasil. Assim dizem os PCN sobre a produção de linguagem:

Produzir linguagem significa produzir discursos. Significa alguém dizer alguma coisa para alguém de uma determinada forma, num determinado contexto histórico. Isso significa que as escolhas feitas ao dizer, ao produzir um discurso não são aleatórias, ainda que possam ser inconscientes, mas decorrentes das condições em que esse discurso é realizado (BRASIL, 1998, p. 25). 
O documento acrescenta ainda que o discurso possui um significado amplo, pois refere-se à atividade comunicativa que acontece em uma determinada situação e abarca tanto os enunciados que lhe deram origem quanto as condições nas quais foi produzido.

Em Schneuwly e Dolz (2013, p. 64), "os gêneros podem ser considerados como instrumentos que fundam a possibilidade de comunicação" em referência ao que diz Bakhtin (2011) afirmando que o gênero do discurso, na verdade, é um megainstrumento que permite agir de forma eficaz numa classe bem definida de situações de comunicação. Os autores veem a escola como lugar de comunicação.

\begin{abstract}
A escola é tomada como autêntico lugar de comunicação, e as situações escolares, como ocasiões de produção/recepção de textos. Os alunos encontram-se assim em múltiplas situações em que a escrita se torna possível e necessária. Mais ainda: o funcionamento da escola pode ser tomado de tal maneira que as ocasiões de produção de textos se multiplicam: na classe, entre alunos; entre classes de uma mesma escola; entre escolas. Isso produz forçosamente novos gêneros, uma forma toda nova de comunicação que produz as formas linguísticas que a possibilitam (SCHNEUWLY, B.; DOLZ, J, 2013, p. 66).
\end{abstract}

Em outras palavras, os autores afirmam que uma determinada situação de comunicação pode ser vista como produtora de novos gêneros a serem trabalhados no âmbito escolar. Os PCN enfatizam que a escola deve propiciar ao aluno o acesso ao universo dos textos que circulam socialmente, ensiná-lo a produzi-los e interpretá-los e que todas as disciplinas têm responsabilidade nesse sentido, mas chama a atenção para o fato de que cabe à disciplina de Língua Portuguesa o papel de fazê-lo de modo sistemático. O ensino de gêneros discursivos da oralidade é tão relevante quanto o ensino de gêneros escritos. $\mathrm{Na}$ seção seguinte, discutiremos aspectos que compõem a oralidade, como entonação e pausa.

\title{
2. Oralidade
}

Fala e escrita possuem traços semelhantes como dialogicidade, usos estratégicos, funções interacionais, envolvimento, situacionalidade e dinamicidade, mas as diferenças entre as duas modalidades acontecem em um continuum tipológico devendo ser vistas na perspectiva do uso e não como características intrínsecas (FÁVERO et al, 2014, p. 13).

As autoras apontam como exemplo desse continuum, por um lado, uma conferência na modalidade oral e um artigo científico na modalidade escrita e, por outro, uma carta familiar e uma conversa espontânea entre amigos. Fávero et al (2014) reforçam a importância de a escola fazer um trabalho de integração fala/escrita tendo em vista que o estudo da oralidade deve ser feito paralelamente ao da escrita.

Em relação à linguagem oral, os PCN esclarecem que o trabalho com esta modalidade "deve acontecer no interior de atividades significativas como seminários, dramatização de textos teatrais, simulação de programas de rádio e TV e de outros usos públicos da língua oral" (BRASIL, 1998, p. 52). Assim, é possível dar sentido e função ao trabalho com aspectos como entonação, dicção, gesto e postura que, no caso da linguagem oral, têm papel complementar para conferir sentido aos textos.

Em Dolz, Schneuwly e Haller (2013, p. 127), “o termo oral do latim os, oris (boca) referese a tudo aquilo que se transmite pela boca. Em oposição ao escrito, o oral se refere à linguagem falada, realizada pelo aparelho fonador". Eles afirmam que a voz humana é, ao mesmo tempo, produzida e ouvida pelo próprio emissor e esse aspecto deve ser levado em consideração para a produção oral. Dessa forma, a voz não produz apenas vogais e consoantes, mas também elementos prosódicos como a entonação e a pausa, elementos que serão abordados em seguida. 
Ainda segundo os autores, não se pode pensar o oral sem a prosódia, isto é, sem a entonação, sem a pausa, pois estes recursos possibilitam diferentes melodias vocais e mostram variações das emoções ou das atitudes do enunciador no momento em que ele se expressa.

No que diz respeito à entonação, Bakhtin e Volochínov (2011, p. 154) dizem que "a palavra na vida não se centra em si mesma, ela aparece na situação extraverbal da vida e conserva com ela o vínculo mais estreito". Para eles, a entonação no discurso diário tem uma capacidade tão metafórica que as palavras parecem ter alma. Assim, a entonação revela que o mundo que circunda o falante tem vida.

É como se a entonação ameaçasse, se indignasse, amasse e acariciasse os objetos e fenômenos inanimados, o que dá uma carga metafórica riquíssima à palavra, ao discurso, enquanto que as metáforas comuns da língua conversacional, em sua maioria se extinguiram e, semanticamente, são pobres e prosaicas (Bakhtin; Volochínov, 2011, p. 154).

Portanto, uma palavra com entonação adequada é plena de sentido e de importância. Os autores ainda destacam que

[..] a entonação e o gesto são ativos e objetivos porque expressam um estado passivo de ânimo do falante e que a entonação segue em duas direções: para o ouvinte e para o objeto da enunciação como se fosse um terceiro participante vivo. Esta dupla orientação determina e atribui um sentido a todos os aspectos da entonação (Bakhtin e Volochínov, 2011, p. 164).

De acordo com Fávero et al (2014), há uma tendência para a presença da oralidade no discurso escrito e esta pode ser uma maneira eficiente de construção de um texto mais envolvente para o leitor. Isso pode ser visto no texto jornalístico, por exemplo, que tem, nas marcas de oralidade na escrita, criatividade e modernidade, pois pode influenciar o leitor criando os efeitos de sentido pretendidos.

Outro elemento a ser considerado é a pausa. Cagliari (1992) afirma que esse elemento prosódico possibilita o falante respirar durante a fala em momentos oportunos. Além disso, por meio desse recurso acontece a segmentação da fala que pode ocorrer depois de frases, sintagmas, palavras e até depois de sílabas quando se silabifica uma palavra, por exemplo. Pode-se também usar a pausa "para indicar o deslocamento de elementos sintáticos para assinalar algum tipo de mudanças de conteúdo semântico, e conduzem a compreensão do ouvinte" (CAGLIARI, 1992). Após essa breve discussão referente aos aspectos que compõem a oralidade, veremos, na seção seguinte, o gênero notícia de rádio.

\section{Notícia de rádio}

Uma das metas declaradas nos PCN é a de possibilitar a compreensão e a produção dos vários gêneros discursivos com os quais o aluno lida no seu cotidiano e não apenas analisar-lhes a estrutura externa. Nesse sentido, entrevistas, anúncios, notícias via rádio e televisão são sugestões do próprio documento para o trabalho com a linguagem oral. Assim diz o documento:

Expressar-se oralmente é algo que requer confiança em si mesmo. Isso se conquista em ambientes favoráveis à manifestação do que se pensa, do que se sente, do que se é. Assim, o desenvolvimento do aluno depende consideravelmente de a escola constituirse num ambiente que respeite e acolha a vez e a voz, a diferença e a diversidade. Mas, sobretudo, depende de a escola ensinar-lhe os usos da língua adequados a diferentes situações comunicativas (BRASIL, 1998, p. 49). 
Dito isto, percebe-se que gêneros da esfera jornalística na sala de aula são uma proposta enriquecedora porque apresentam temas atuais e possibilitam aos alunos debates, defesa de pontos de vista e discordância de opiniões. Normalmente, as situações criadas para a produção de textos são permeadas por discussões, são interativas e polifônicas e este aspecto merece atenção, pois contribui para o desenvolvimento da competência discursiva dos alunos.

Assim, a notícia é um gênero que pode e deve ser trabalhado na escola, tendo em vista a necessidade de o aluno informar-se e manter-se atualizado. Estudando a notícia, ao mesmo tempo que ele aprende as especificidades do gênero, tem contato com temas diversos que merecem reflexão e discussão.

Do ponto de vista da estrutura, Lage (2006, p. 17) define o gênero notícia como "o relato de uma série de fatos, a partir do acontecimento mais importante ou interessante". Essa definição vai ao encontro dos aspectos tipológicos de Dolz e Schneuwly (2013), em que o gênero notícia encontra-se na ordem do relatar.

A notícia como relato também é reforçada em BALTAR (2006, p. 133) que afirma que "notícia é o gênero básico do jornalismo em que se relata um fato do cotidiano considerado importante, mas sem opinião". O autor destaca que a notícia é um gênero genuinamente informativo.

A notícia radiofônica apresenta particularidades interessantes, pois apresenta-se por meio de um tipo de linguagem que oferece pistas para o exercício de uma escuta atenta aos elementos sensoriais, potenciais, que fazem aflorar a fantasia, a imaginação, tornando o ouvinte um sujeito daquela transmissão (GOLIM, 2005).

Em Porchat (1989), "contar apenas com audição significa que o som deverá suprir a falta de imagem e isso requer uma linguagem mais do que clara, uma linguagem nítida, inconfundível, para que o ouvinte veja através das palavras" (PORCHAT, 1989, p. 89). Escutar, portanto, é uma experiência que estimula a escuta de nós mesmos e a escuta dos outros. A linguagem radiofônica permite que, por meio do som, o ouvinte sinta e veja o que está sendo dito e está se passando consigo no momento em que escuta. Além disso, na comunicação radiofônica, é importante levar em consideração a tendência ao desvio de atenção por parte do ouvinte e da possibilidade de que ele mude de estação a qualquer momento.

De acordo com Baltar (2012), quando se escreve para o rádio, escreve-se para ser ouvido, não para ser lido, o que torna peculiar a escrita de textos para esse suporte. Desse modo, durante a produção do texto, é necessário levarmos em conta as restrições do canal auditivo que interferem na recepção dos textos. Tendo em vista que esse tipo de comunicação não oferece a possibilidade de releitura, o texto no rádio não poderá ser retomado e este aspecto deve ser considerado no momento da produção textual. A seguir, faremos a apresentação da proposta didática com o gênero notícia de rádio.

\section{Apresentação da proposta didática}

\subsection{Introdução}

Levar o aluno a perceber a importância de ler e estar informado é um desafio para a escola. Vivemos em uma época marcada pela infinidade de atrativos como são os produtos da tecnologia digital cujo foco é o lazer e usos voltados para a vida pessoal. Na escola pública, podem ser desenvolvidas atividades na disciplina de Língua Portuguesa que façam da leitura e escuta atividades primordiais. Necessário é atentar-se para o fato de que a leitura em suportes provenientes do meio digital não é acessível a todos os estudantes de escola pública. Assim, a escola deve promover a leitura que mantenha nossos alunos atualizados e aptos a discutirem sobre acontecimentos relevantes. Além disso, a leitura apresenta-se como ferramenta de interação e representa, seguramente, oportunidade de reflexão e debate para os alunos. 
A escola, portanto, deve promover uma leitura que instigue o aluno a fazer indagações a respeito dos fatos que acontecem em seu dia a dia. Assim, a leitura de notícias pode e deve ser desenvolvida e estimulada no ambiente escolar, pois muito pode contribuir para a formação do aluno como leitor e como cidadão.

A aplicação dessa proposta visa a inserir práticas de oralidade, a conferir se é possível, a partir da leitura de notícias de rádio, promover reflexão e discussão sobre temas da atualidade que afetam direta ou indiretamente a realidade do aluno.

Partimos de uma concepção interacional da língua que concebe o ato da leitura como produto da relação entre autor, texto e leitor/ouvinte.

Este trabalho tem o objetivo de promover essa interação e, consequentemente, discussão sobre diversos temas diariamente em pauta na mídia e, mais especificamente, o veículo rádio. $\mathrm{O}$ ponto de partida de nosso estudo é a proposta de leitura e escuta de notícias em radiojornais.

\subsection{Descrição metodológica}

Adotamos o modelo de sequência didática proposto por Dolz, Noverraz e Schneuwly (2013). A proposta foi desenvolvida da seguinte forma:

- Introdução

- Apresentação da sequência didática- $1 \mathrm{~h} / \mathrm{aula}^{5}$

- Produção inicial-1 h/aula

- Quatro módulos- Módulo I - 2 aulas; Módulo II - 2 aulas; Módulo III - 2 aulas; Módulo IV- 2 aulas ( $8 \mathrm{~h} /$ aula no total);

- Produção final $-2 \mathrm{~h} /$ aula

- Total: $12 \mathrm{~h} /$ aula

\subsection{Sequência Didática}

\subsubsection{Apresentação}

\section{$1^{\mathrm{a}}$ aula}

Nesta primeira aula, os alunos terão contato com notícias de rádio, jornal, internet, para que percebam como a notícia circula pela sociedade e como este gênero dialoga com variados temas. A escolha deste gênero justifica-se pelo fato de que vivemos em uma época em que somos bombardeados por notícias e é importante o aluno dar-se conta disso e, principalmente, saber o que merece sua atenção. Falaremos sobre a produção final, isto é, que ao término dos módulos os alunos farão a apresentação de um radiojornal na escola.

\subsubsection{Produção inicial}

\section{$2^{\mathrm{a}}$ aula}

Nesta aula, solicitaremos que os alunos escrevam alguma notícia da qual se lembrem e, caso não recordem de nenhuma, criem, inventem para ser lida em um programa de rádio. Logo depois, utilizando notícias de diversos suportes como rádio, jornal e internet, será apresentada a notícia e suas especificidades.

Será aberta discussão oral a respeito das notícias. Serão consideradas as seguintes questões norteadoras:

a) Para você, o que é importante destacar nessas notícias?

\footnotetext{
${ }^{5}$ Uma hora/aula corresponde a 50 minutos.
} 
b) Que discussões podemos promover a partir dessa leitura?

Os alunos recebem estas questões impressas para registrar suas opiniões por escrito e, em outros momentos, esta atividade pode ser realizada oralmente. Assim, abre-se espaço para que os alunos se expressem verbalizando suas opiniões.

Como forma de avaliação, será feita uma apreciação das respostas dadas pelos alunos às questões suscitadas pela leitura e escuta dos textos.

\subsubsection{Módulo I - Leitura e escrita}

\section{$3^{\text {a }}$ aula}

Depois da produção inicial, apresentaremos e discutiremos algumas notícias impressas, no sentido de verificar a estrutura composicional. Serão apresentados os elementos estruturais da notícia: manchete, lide e corpo. Os alunos terão contato com o lide, isto é, as seis perguntas que normalmente compõem o primeiro parágrafo da notícia: o quê, quando, quem, como, onde, por quê/para quê.

Objetivo: Introduzir os elementos estruturais da notícia: manchete, lide e corpo.

Conteúdo: Leitura e atividades.

Recursos: Serão utilizados exemplares de notícias.

Procedimentos metodológicos: Apresentaremos as notícias para que os alunos encontrem os elementos estudados. Iniciaremos a aula com uma apresentação dos elementos, por meio de aula expositiva.

Avaliação: Será feita a apreciação dos comentários dos alunos ao questionamento.

\section{$4^{a}$ Aula: Leitura expressiva}

Nesta aula, o foco será a leitura expressiva das notícias de rádio. Apresentaremos a entonação ascendente e descendente e solicitaremos aos alunos que registrem nas notícias essas marcas conforme o público da emissora. Eles devem perceber que a entonação empregada está relacionada ao público-alvo. Por exemplo, se a rádio for voltada ao público jovem e popular, utiliza-se a entonação ascendente (menos monitoramento), se adulto, utiliza-se a entonação descendente (que imprime mais monitoramento). Dividiremos a turma em duplas e iniciaremos a leitura em voz alta. Os alunos lerão entre eles e depois para a turma.

Objetivo: Praticar leitura expressiva de notícias.

Conteúdos: Notícias distribuídas para os alunos.

Recursos: Serão feitas cópias de notícias.

Procedimentos metodológicos: O professor lerá com a turma algumas notícias, enfatizando a entonação ascendente e descendente para mostrar como a entonação imprime uma certa musicalidade ao texto, com contornos de altos e baixos responsáveis pela melodia e para marcar a informação que se quer destacar.

\subsubsection{Módulo II - Práticas de oralidade e leitura expressiva}

\section{$5^{\mathrm{a}}$ aula}

Serão distribuídos notícias e poemas para que os alunos, em duplas, leiam em voz alta. Optamos por incluir o gênero poema por considerarmos este gênero muito apropriado para que os alunos percebam a diferença da entonação a ser utilizada em cada um dos gêneros no momento da leitura. Os alunos, em dupla, recebem os textos. Um aluno lê o poema e o outro a notícia. Depois, modifica-se a ordem estabelecida, o que leu a notícia, lê o poema, e o aluno que leu o poema, lê a notícia. Cria-se, assim, um espaço para que eles interajam e troquem informações a respeito das leituras. 
É importante que os alunos percebam que a leitura dos dois gêneros é distinta, isto é, a leitura da notícia exige uma maior objetividade e seriedade. Já a leitura do poema é mais subjetiva e dá ao locutor maior liberdade na interpretação.

Como forma de avaliação, será feita uma leitura expressiva de notícias e poemas.

\section{$6^{\mathrm{a}}$ aula}

Haverá a continuação da leitura de notícias em sala de aula. Prossegue-se com a leitura das notícias e agora o elemento a ser abordado é a pausa. Este tópico será muito importante para melhorar a expressividade na leitura dos alunos. Será um momento interessante, pois o professor, ao ler e mostrar a marcação das pausas curtas e longas, dialogará com a turma, mostrando como se faz, confirmando que essa marca prosódica contribui para a construção do sentido e compreensão do texto. Alguns alunos poderão encontrar dificuldades e o professor pode fazer um trabalho individualizado com eles.

Para Cagliari (1992), a pausa tem uma função que possibilita o falante respirar durante a fala em momentos oportunos. Estes momentos ocorrem sempre entre grupos tonais no final de conjunto de orações chamados de períodos, ou seja, uma oração ou conjunto de orações com estrutura sintática e sentido completos. Outra função que a pausa tem, de acordo com o autor é a de segmentação da fala, podendo ocorrer depois de frases, sintagmas, palavras e até depois de sílabas quando se silabifica uma palavra, por exemplo. "Usa-se também a pausa para indicar o deslocamento de elementos sintáticos para assinalar algum tipo de mudança brusca ou radical do conteúdo semântico, que vai se iniciar ou terminar" (CAGLIARI, 1992, p. 47).

Objetivos: Dar continuidade à leitura com marcação das pausas.

Conteúdos: Marcação de pausas curtas e longas.

Recursos: Serão feitas cópia das notícias.

Procedimentos metodológicos: A turma será dividida mais uma vez em duplas e será iniciada a leitura em voz alta de cada dupla para verificar a marcação tanto da entonação ascendente e descendente quanto das pausas curta e longa. Em seguida, voltaremos à discussão e compreensão do que foi lido, estabelecendo relação da compreensão com os elementos destacados. Este momento da aula pode ser muito enriquecedor, tendo em vista a troca de opiniões e impressões sobre a leitura e o tema da aula. Os alunos podem responder a algumas perguntas a serem preparadas para que o professor tenha um retorno deles a respeito do conteúdo apresentado.

Avaliação: Serão considerados a conversa e o registro das impressões dos alunos a partir da leitura realizada.

\subsubsection{Módulo III - Radiojornal}

\section{$7^{\mathrm{a}}$ aula}

Neste momento, será apresentado aos alunos um radiojornal.

Objetivo: Levar o aluno a conhecer um radiojornal.

Conteúdos: Escuta e compreensão de algumas notícias.

Recursos: Serão utilizados computador e pendrive.

\section{$8^{\mathrm{a}}$ aula}

Depois de ouvirem o radiojornal, os alunos serão convidados a sugerir assuntos para serem tratados na produção final, ou seja, notícias que aconteceram ou vão acontecer na escola ou na comunidade, por exemplo. O professor poderá propor na sala de aula um debate amplo sobre o que eles poderiam incluir. Neste momento, alunos e professor decidem como será realizada a apresentação do radiojornal. Devem decidir também se a apresentação será gravada ou 
ao vivo. Se for ao vivo, as notícias deverão ser transcritas ${ }^{6}$ para depois serem lidas. Se for gravado, as matérias feitas pelos alunos precisam passar por um processo de edição que pode ser feito em um programa de áudio chamado audacity.

Objetivo: Tecer um quadro geral sobre como será a produção final.

Conteúdo: Discussão a respeito da produção e apresentação do radiojornal pelos alunos.

Recursos: Serão utilizados lousa e papel.

Procedimentos metodológicos: Será feita uma discussão geral sobre a apresentação do radiojornal. Os alunos sugerem assuntos que farão parte do radiojornal. Cada aluno participa comentando os motivos pelos quais incluiriam ou retirariam determinada notícia, por exemplo. Esta parte é fundamental no desenvolvimento da proposta, pois, ao pensar a produção final, os alunos podem deixar evidente em que medida estão envolvidos. A turma será dividida em grupos e o professor fará a intermediação dos turnos de fala para que todos possam expor suas impressões e comentários sobre o radiojornal a ser preparado.

\subsubsection{Módulo IV - Produção}

\section{$9^{\mathrm{a}}$ e $10^{\mathrm{a}}$ aulas}

Estas aulas serão reservadas para a produção dos textos sobre fatos que ocorreram ou ocorrerão na escola ou na comunidade. Será proposta aos alunos a tarefa de gravar o conteúdo de notícias previamente selecionadas. O professor organizará a sala em grupos a fim de que todos possam redigir as notícias e gravá-las. Depois, elas serão reunidas de acordo com o roteiro a ser preparado junto com os alunos.

Objetivo: Produzir notícias.

Conteúdo: Produção de notícias pelos alunos.

Recursos: Será utilizado celular ou gravador portátil.

Avaliação: Será avaliada a produção gravada.

\subsubsection{Organização do material e apresentação da produção final}

\section{$11^{\mathrm{a}}$ e $12^{\mathrm{a}}$ aulas}

Nessas aulas acontece a preparação do radiojornal. O professor, junto com os alunos, seleciona, reúne, retira, inclui, faz a edição das produções para a apresentação na sala de aula.

A produção final será a escuta do radiojornal pelos alunos da turma e depois pelos alunos da escola, na hora do Intervalo.

\subsubsection{Avaliação}

A avaliação será feita ao longo de todo o desenvolvimento da Sequência Didática. Desta forma, o aluno terá condições de refletir sobre o seu aprendizado e o professor terá um retorno dos resultados da aplicação das atividades.

Para trabalhar com as modalidades oral e escrita em sala de aula, optamos pela produção e apresentação de um programa de rádio. Acreditamos que esta escolha é relevante para o $7^{\circ}$ ano do Ensino Fundamental, uma vez que contempla as duas modalidades da língua. Além do binômio ler/escrever, será enfatizado o binômio falar/ouvir como recomendam os PCN (1998). Nas atividades propostas, os alunos poderão perceber as características da modalidade oral, utilizando uma linguagem simples, concisa e objetiva como a radiofônica.

\footnotetext{
${ }^{6}$ A transcrição é entendida aqui como a transposição do oral para o escrito. O professor pode também fazer atividades de retextualização para adequar o texto à modalidade escrita da língua.

${ }^{7}$ Software sugerido e apresentado em detalhes para esse tipo de trabalho por Baltar (2012, p. 76), o qual observa que este é um "[...] software, livre e gratuito, para gravação, edição e reprodução de áudio".
} 


\section{CONSIDERAÇÕES FINAIS}

Esse artigo buscou apresentar uma proposta didática que contemplasse práticas de oralidade e escrita nas aulas de Língua Portuguesa com a produção e leitura de notícias de rádio.

A oralidade e a escrita possuem inter-relações que, muitas vezes, não são percebidas pelos alunos, visto que ainda não é tradição na escola enfatizar a modalidade oral da língua. Pelo percurso feito até aqui, constata-se que as duas modalidades devem ter lugar no ensino de língua materna, sem que se priorize uma delas em detrimento da outra. Ambas devem ser ensinadas, pois fazem parte do mesmo sistema linguístico.

Acreditamos que, partindo de trabalhos sistematizados e voltados para atividades com a modalidade oral da língua, este eixo pode vir a tornar-se conteúdo regular da disciplina de Língua Portuguesa.

Sabe-se que, neste sentido, há muito a ser feito e, seguramente, a inclusão dessa prática discursiva contribuirá para a atuação do aluno como cidadão que participa e discute problemas e questões importantes para sua vida e para a comunidade onde vive.

A oralidade na sala de aula continua sendo um desafio, pois apesar de já haver certo consenso da comunidade acadêmica na área da Linguística quanto à importância dessa modalidade, ainda há escassez de material didático sistematizado voltado para essa vertente da língua.

Ademais, tendo em vista que o aluno não está acostumado a ouvir sua voz, este é um universo a ser explorado em sala de aula, pois são muitas as possibilidades de abordagem e enfoque do ensino/aprendizado da língua. Nossa proposta inclui a escrita, a leitura em voz alta, a gravação e a escuta dessa leitura.

De início, como algo que não é comum, há certa dificuldade tanto por parte dos alunos, quanto dos professores, mas, ao longo de um trabalho contínuo e regular, as práticas de oralidade em nossas salas de aula serão tão comuns como as de escrita e isso poderá gerar reflexos positivos no desempenho comunicativo e linguístico de nossos alunos.

\section{REFERÊNCIAS BIBLIOGRÁFICAS}

BAKHTIN, M. Estética da criação verbal. São Paulo: Martins Fontes, 2010.

BAKHTIN, M. e VOLOCHÍNOV. Palavra própria e palavra outra na sintaxe da enunciação. São Paulo: Pedro \& João Editores, 2011.

BALTAR, M. Competência discursiva e gêneros textuais: uma experiência com o jornal em sala de aula, 2. Ed. Caxias do Sul: EDUCS, 2006.

BALTAR, M. Rádio escolar: uma experiência de letramento midiático. São Paulo: Cortez, 2012.

BRASIL. Ministério da Educação e do Desporto. Parâmetros Curriculares Nacionais. Brasília, 1998.

CAGLIARI, L. C. Da importância prosódica de fatos gramaticais. In: ILARI, R. (Org). Gramática do português falado. Vol II: Níveis de análise linguística. Campinas: Editora da Unicamp,1992.

DOLZ, J.; NOVERRAZ, M.; SCHNEUWLY, B. Sequências didáticas para o oral e a escrita: apresentação de um procedimento. In: SCHNEUWLY, B.; DOLZ, J. Gêneros orais e escritos na escola. São Paulo: Mercado das Letras, 2013, p. 81-108. 
DOLZ, J.; SCHNEUWLY, B. Gêneros e progressão em expressão oral e escrita - elementos para reflexões sobre uma experiência suíça (francófona). In: SCHNEUWLY, B.; DOLZ, J. Gêneros orais e escritos na escola. São Paulo: Mercado das Letras, 2013, p. 35-60.

DOLZ, J.; SCHNEUWLY, B; HALLER, S. O oral como texto: como construir um objeto de ensino. In: SCHNEUWLY, B.; DOLZ, J. Gêneros orais e escritos na escola. São Paulo: Mercado das Letras, 2013, p. 125-155.

FÁVERO, L. L. A entrevista na fala e na escrita. In: PRETTI, D. (Org.). Fala e escrita em questão. São Paulo: Humanitas, 2000.

FÁVERO, L. L.; ANDRADE, M. L. C. V. O; AQUINO, Z. In: reflexões sobre oralidade e escrita no ensino de Língua Portuguesa. ELIAS, V. (Org.). São Paulo: Contexto, 2014.

FERRARETO, L. A. Rádio: o veículo, a história e a técnica. São Paulo: Sagra Luzzatto, 2001.

GOLIM, Cida. Teorias do rádio: Paul Zumthor e a poética da voz. In: Intercom - Sociedade Brasileira de Estudos Interdisciplinares da Comunicação XXVIII Congresso Brasileiro de Ciências da Comunicação - UERJ - 5 a 9 de setembro de 2005.

LAGE, N. Estrutura da notícia. São Paulo: Ática, 2006.

MARCUSCHI, Luis Antônio. A oralidade e o ensino de língua: uma questão pouco falada. In: DIONÍSIO, Ângela, Paiva e BEZERRA, Maria Auxiliadora. (Org). O livro didático de português: múltiplos olhares. Rio de Janeiro: Lucerna, 2001.

2008.

Produção textual: Análise de gêneros e compreensão. São Paulo: Parábola Editorial,

PORCHAT, Maria Elisa. Manual de Radiojornalismo: Jovem Pan. $2^{a}$ edição. São Paulo: Ática, 1989.

SCHNEUWLY, B. Gêneros e tipos de discurso: considerações psicológicas e ontogenéticas. In: SCHNEUWLY, B.; DOLZ, J. Gêneros orais e escritos na escola. São Paulo: Mercado das Letras, 2013, p. 19-34.

SCHNEUWLY, B; DOLZ, J. Os gêneros escolares - das práticas de linguagem aos objetos de ensino. In: SCHNEUWLY, B.; DOLZ, J. Gêneros orais e escritos na escola. São Paulo: Mercado das Letras, 2013, p. 61-78.

THIOLLENT, M. Metodologia da pesquisa-ação. São Paulo: Cortez, 2011.

Recebido em 31/05/2017

Aceito em 23/08/2017

Publicado em 23/08/2017 